\title{
THE INTERACTION OF HABITAT FRAGMENTATION, PLANT, AND SMALL MAMMAL SUCCESSION IN AN OLD FIELD
}

\author{
E. William Schweiger,,${ }^{1,4}$ James E. Diffendorfer,${ }^{2}$ Robert D. Holt,${ }^{1}$ Raymond Pierotti, ${ }^{1}$ \\ AND Michael S. GAINES ${ }^{3}$ \\ ${ }^{1}$ Department of Systematics and Ecology, University of Kansas, Lawrence, Kansas 66045 USA \\ ${ }^{2}$ Department of Biology, 5500 Campanile Drive, San Diego State University, San Diego, California 92182 USA \\ ${ }^{3}$ Department of Biology, P.O. Box 249118, University of Miami, Coral Gables, Florida 33133 USA
}

\begin{abstract}
We compared the density and spatial distribution of four small mammal species (Microtus ochrogaster, Peromyscus maniculatus, Sigmodon hispidus, and P. leucopus) along with general measures of an old field plant community across two successional phases (1984-1986 and 1994-1996) of an experimental study of fragmentation in eastern Kansas. During the early phase the plant community was characterized by little spatial or temporal variance across patch size, consistent with spatially neutral models of succession. In contrast, there was a strong, species-specific effect of patch size on small mammal species distribution and abundance. The lack of variance in vegetation structure across patch size during the early seres suggests that small mammal distributions were responding in large part to features of the system other than variance in vegetation structure and composition across patch size.
\end{abstract}

As succession proceeded, the colonization of the system by woody plant species precipitated a series of patch size effects on plant community composition. Differential habitat selection by small mammals at the patch scale tracked these changes in plant distribution. For example, $M$. ochrogaster and $S$. hispidus shifted their distributions away from less fragmented patches toward smaller patches, where retarded plant succession had maintained an earlier sere. P. leucopus successfully colonized and maintained high densities only on large patches, where plant succession had progressed most rapidly toward a woody-speciesdominated community.

Our results highlight the role of landscape structure in long-term community dynamics and indicate that some of the complexity observed in successional systems may result from the structure and composition of the landscape mosaic. In general, our results suggest that to fully understand long-term change within communities, the influence of landscape structure on patterns of heterogeneity in both vegetation and consumer dynamics must be understood. Moreover, the long-term and landscape-scale perspectives afforded by our study provide insight into community dynamics that might otherwise be missed.

Key words: community structure; habitat accommodation model; habitat fragmentation; habitat selection; interspecific competition; patch size; small mammals; spatial dynamics; succession.

\section{INTRODUCTION}

Habitat fragmentation alters naturally existing landscape mosaics (Soule 1986, Saunders et al. 1991, Wiens 1995) and may affect numerous ecological processes across multiple spatial scales (Simberloff 1988, Kareiva 1990, Soule et al. 1992). These effects include changes in abiotic regimes (Saunders et al. 1991), shifts in habitat use (Kareiva 1987, Lavorel et al. 1994), altered population dynamics (Pulliam 1988, Pulliam and Danielson 1992, Diffendorfer et al. 1995b), and shifts in community composition (Usher 1987, Diffendorfer et al. 1996, Turner 1996). However, the impact of fragmentation on long-term ecological processes, such as succession, is still largely unknown (Holt et al. 1995).

Manuscript received 22 June 1998; revised 18 March 1999; accepted 11 May 1999; final version received 3 June 1999.

${ }^{4}$ Present address: NHEERL, Mid-continent Ecology Division, U.S. EPA (8EPR-EP), 999 18th Street, Suite 500, Denver, Colorado 80202 USA.
Secondary succession has been thoroughly studied, especially within old fields (e.g., Gleason 1928, Egler 1954, Connell and Slatyer 1977, Tilman 1987, Bazzaz 1990). Yet, in over a thousand studies reviewed by M. Rejmánek (personal communication) very few experiments looked explicitly at the effect of patch size or other landscape metrics on succession (see also Phillips and Shure 1990, Glenn-Lewin et al. 1992, Holt et al. 1995). Studies of long-term temporal dynamics have emphasized local mechanisms such as competition, herbivory, and variation in life history strategies as the factors driving successional shifts in community composition (e.g., Glenn-Lewin 1980, Inouye et al. 1987, Tilman 1988, Bazzaz 1990, Davidson 1993, Halpern et al. 1997).

Furthermore, most studies of succession have focused on directional change in vegetation, with less attention paid to consumer guilds that may simultaneously undergo succession. The few studies docu- 


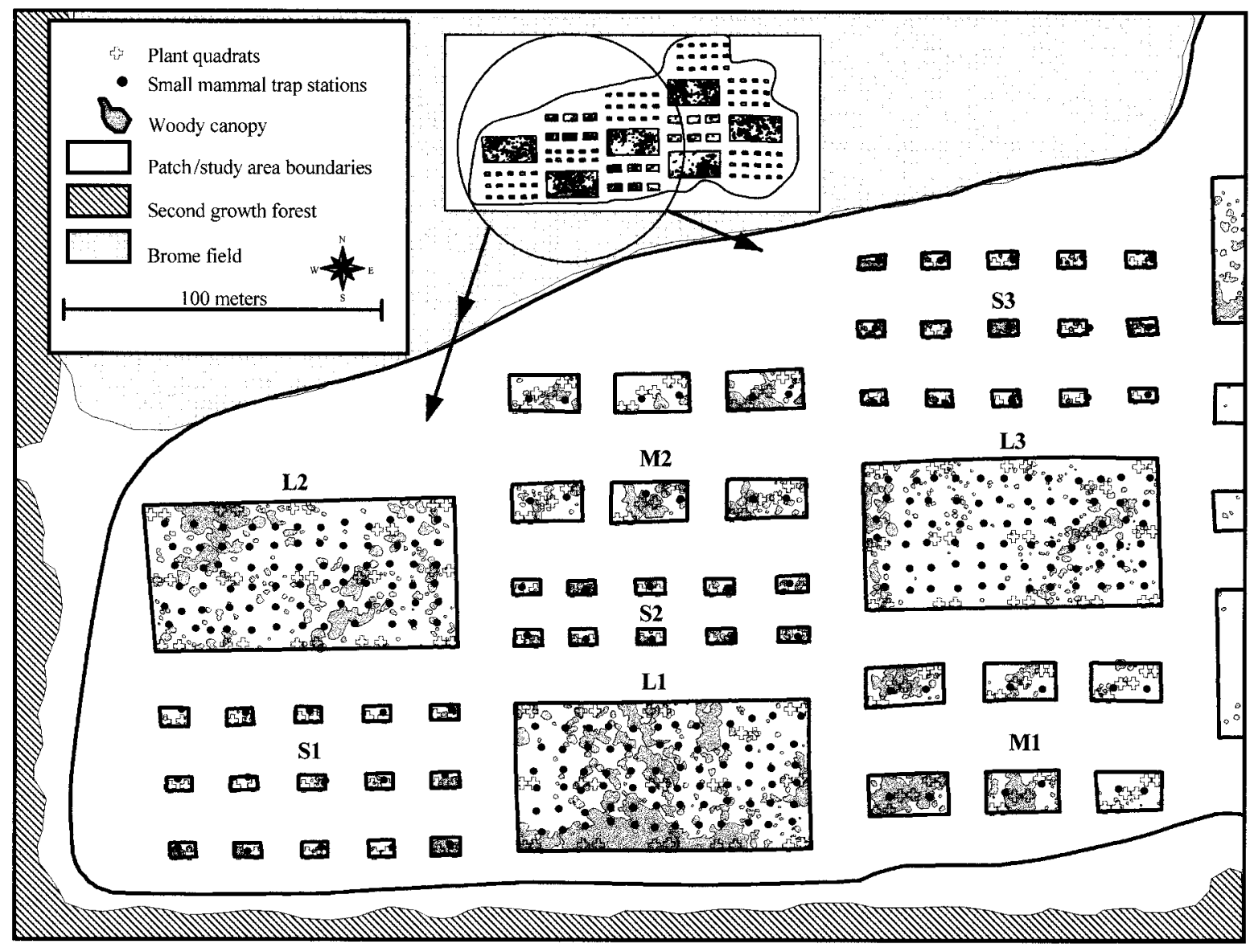

FIG. 1. Map of the west half of the Kansas Fragmentation Project, $12 \mathrm{~km}$ northeast of Lawrence, Kansas, USA (the entire site is shown in the inset). The system consists of 104 patches allowed to undergo succession since their creation in 1984 (the intervening interstitial areas have been regularly mown). Patches are grouped into 15 blocks (eight on the west half), each measuring $50 \times 100 \mathrm{~m}$. Each of these blocks is assigned to one of the following treatments: a single $50 \times 100 \mathrm{~m}$ patch (large blocks); six $12 \times 24 \mathrm{~m}$ patches (medium blocks); or 10-15 small $4 \times 8 \mathrm{~m}$ patches (small blocks). Patches within small and medium blocks are separated by 20-30 m of interstitial habitat. The study site is surrounded by oak-hickory forest to the west and south and brome field to the north (the eastern edge, not shown in the figure, is bordered by mixed forest and pastureland). The trapping grid (black dots) consists of 280 trap stations. The $1 \times 1 \mathrm{~m}$ plant sampling quadrats are shown with crosses. The $4 \times 4 \mathrm{~m}$ quadrats (not shown) are centered on the locations of the $1 \times 1 \mathrm{~m}$ quadrats. Dense woody canopy within each patch is indicated with dark, irregularly shaped polygons. All features were hand-digitized from orthophotos taken in 1994 and rectified using standard techniques in a Geographic Information System.

menting succession within animal communities suggest that animal succession mirrors shifts in local plant species composition and habitat structure (Pearson 1959, Sly 1976, Atkeson and Johnson 1978, MacMahon 1981, Fox 1982, 1990, 1995, Huntly and Inouye 1987, Whitford and Steinberger 1989, Sietman et al. 1994). However, consumer communities are likely to respond to fragmentation (e.g., patch size), even if all fragments have the same vegetation composition. If plant succession occurs differently on different-sized habitat fragments (see Holt et al. 1995 for possible mechanisms), the overall pattern of spatial variation in the consumer community may reflect a combination of individual and population responses to both landscape features and to shifts in local vegetation.

In addition to tracking changes in vegetation, con- sumers influence old field succession. For instance, herbivory by microtine rodents on seedlings can strongly affect woody plant recruitment into old fields (e.g., Byers 1985, Schupp 1988, Gill and Marks 1991, Davidson 1993, Ostfeld and Canham 1993, Ostfeld et al. 1994, 1997). Small mammals can also potentially influence plant dynamics by seed predation. For example, cricetid rodents can consume large amounts of tree seeds in old fields (Janzen 1971, Gill and Marks 1991, Bowers and Dooley 1993) and thereby delay colonization. Given that small mammals may alter rates of woody species establishment, fragmentation effects on plant succession could result indirectly from fragmentation effects on the small mammal community.

In this paper, we use a long-term experimental study of fragmentation and succession in eastern Kansas to 
examine the effects of spatial structure on successional processes within an old field plant and small mammal community. For a description of the site see Figure 1, Foster and Gaines (1991), Robinson et al. (1992), Holt et al. (1995), and Diffendorfer et al. (1995a, $b, 1996)$. Prior studies in our system have documented in detail fragmentation effects on small mammal species composition and demography (Foster and Gaines 1991, Diffendorfer et al. 1995b), dispersal (Diffendorfer et al. $1995 a$ ), and plant colonization and succession (Holt et al. 1995, Yao et al. 1999). The most abundant small mammal species on our site include prairie voles $(M i$ crotus ochrogaster), deer and white-footed mice (Peromyscus maniculatus, $P$. leucopus), and cotton rats (Sigmodon hispidus). The design of the system, including the three patch sizes and the distances between patches, was based on the biology of the small mammal and dominant plant species in the system. We consider our study area proper (the patches and interstitial habitat [Fig. 1]) plus the surrounding forest and brome fields that are potential sources of dispersers, to be a functional landscape for the focal species of our study (Wiens et al. 1993, Lidicker 1995, Krohne 1997).

\section{Small mammal succession: the habitat accommodation model}

Fox $(1982,1990,1995)$ developed a verbal model for small mammal succession, the habitat accommodation model, based upon the well-documented correlation between local vegetation features and small mammal distributions (e.g., Cockburn and Lidicker 1983, Rosenzweig 1989, Hanski 1990, Kelt et al. 1994). Fox's model suggests small mammal succession arises because species respond to temporal shifts in vegetative composition, reflecting species-specific habitat requirements and interspecific competitive interactions. Small mammal species occur in a successional sequence when local conditions have changed such that a specie's realized niche requirements are met. Continued small mammal succession occurs when local habitat conditions change and a species relative abundance is reduced or it is replaced by better suited species (Fox 1995).

Analyses of data from our system collected from 1984-1991 indicated that small mammal population density and community composition were strongly influenced by patch size (Foster and Gaines 1991, Gaines et al. 1992 $a, b$, Diffendorfer et al. 1995a, $b$; see also Dooley and Bowers 1996, Collins and Barrett 1997). However, because the effects of patch size on small mammal density and community composition were relatively constant over these seven years (compare Foster and Gaines [1991], Gaines et al. [1992a, b], and Diffendorfer et al. [1995a, b]), there were no resolvable patch size effects on successional patterns in the small mammal community. Holt et al. (1995) report that there were few effects of patch size on successional change in vegetative cover or other gross measure of plant community structure during the first seven years of our study. Thus, differences in small mammal distribution and community composition across patch size during this time were probably not influenced by differences in vegetative composition and structure across patch size. Rather, Foster and Gaines (1991), Gaines et al. (1992a), and Diffendorfer et al. (1996) suggest that minimum patch size requirements and competitive exclusion were responsible for the patterns in small mammal abundance across patch size.

\section{Hypotheses: landscape effects on small mammal succession}

We hypothesized that the pattern of succession in the small mammal community should vary with patch size, particularly given effects of patch size on plant succession. To use Fox's terminology, patch size may be an attribute of habitat that small mammal succession indirectly "accommodates." To test this hypothesis, we contrast measures of the vegetation and small mammal communities generated from data collected September 1984-August 1987 ("early" successional phase) and January 1994-December 1996 ("late" successional phase). Our plant community measures include cover estimates grouped by life form (Raunkiaer 1934, Huntly and Inouye 1987) and an index of community similarity (Horn 1966, Wolda 1981). Our small mammal metrics include mean population density (Jolly 1965, Seber 1973) and the distribution of the proportion of captures at each trap station (Conover 1980, Syrjala 1996). Our hypothesis predicts that small mammal density and distribution of capture proportions will vary with successional phase over the entire study area and across the three patch sizes. This allows succession of the small mammal community to be a function of shifts in the carrying capacity of the entire landscape or a specific patch size. Specific successional patterns in the plant community are assessed in more detail elsewhere (Holt et al. 1995, Yao et al. 1999) and we focus on small mammal succession here.

\section{Methods}

We chose to analyze two distinct phases of succession rather than a continuous series of data for two reasons. First, we wanted to maximize the contrast in metrics generated from each successional stage (Fox 1995). Second, these two intervals represent years with sufficiently detailed, temporally parallel plant and small mammal data sets. Where appropriate, we do interpret data from intervening years (see also Foster and Gaines 1991, Gaines et al. 1992a, $b$, Diffendorfer et. al 1995a, $b, 1996)$. All data used in the analyses presented below are from the 55 patches on the west half of our site (Fig. 1) because this area is where the small mammal trapping has been performed. We use "block size" interchangeably with patch size. Block size refers to blocks of similarly sized patches that we 
treat as experimental units for many of our analyses (Fig. 1).

\section{Field procedures}

Plant sampling.-Permanent $1 \times 1 \mathrm{~m}$ quadrats were established in each patch in 1984 (Foster and Gaines 1991; Fig. 1). Identification, height, and percent cover estimates for all plant species within the quadrats were collected three times a year (late spring, mid-summer, and early fall) from 1984 to 1987, using a point-intercept technique (Goodall 1952). Beginning in 1987, the increasing height and structural complexity of the vegetation necessitated the use of a visual cover estimation technique instead of the point-intercept method, and reduction of sampling frequency to a single mid-summer sample. Data collected from these two sampling techniques are highly correlated.

Woody plants are typically larger than herbaceous plants, and crowns of individual saplings often exceed one square meter (Harper 1977). To account for this size difference, $4 \times 4 \mathrm{~m}$ quadrats (centered on each 1 $\times 1 \mathrm{~m}$ quadrat) were established in 1990 . All woody stems in these quadrats $>0.5 \mathrm{~m}$ in height were identified and counted in 1990. In 1992 and 1994, stems $>2.0 \mathrm{~m}$ in height were identified, counted, and measured (diameter at base and breast height). Beginning in 1995, counts of all stems and measurements of stems $>2.0 \mathrm{~m}$ in height within the $4 \times 4 \mathrm{~m}$ quadrats were conducted.

All taxonomic ambiguities over the years were resolved conservatively by lumping questionable plant taxa into higher classifications. Taxonomy followed the Great Plains Flora Association (1986). For more details on the plant sampling protocol see Holt et al. (1995).

Mammal sampling.-From August 1984 to May 1992, small mammals were trapped every other week with checks on two consecutive mornings and the intervening afternoon (Foster and Gaines 1991, Gaines et al. 1992a, b). From January 1994 to December 1996, trapping was conducted once a month for three days with checks each morning. Sherman live-traps, baited with chicken scratch or crimped oats and supplied with cotton for bedding (in the colder months of the year), were used throughout the study. Upon capture, each animal's weight, sex, reproductive condition, location of capture, and ear tag number were recorded. The same trapping grid has been used throughout the study (Fig. 1).

\section{Vegetation measures}

We used measures of vegetation composition and structure important in structuring small mammal distribution and demography (e.g., Kaufman and Fleharty 1974, Cockburn and Lidicker 1983, Huntly and Inouye 1987, Rosenzweig 1989). Our analyses of these metrics were designed to reveal interactions between block size and successional phase indicative of patch size influences on vegetation succession (all statistical protocols are described in a separate section below).
Vegetative cover.-The quality, composition, and extent of vegetative cover are crucial habitat components for small mammal species (Bergeron and Jodoin 1987, Adler and Wilson 1989). Therefore, we used species-specific cover estimates grouped by life form category (grass, forb, and woody; Raunkiaer 1934, Huntly and Inouye 1987) as a measure of this important niche component. To match the timing of the 1994-1996 samples, the summer samples of 1985 and 1986 were used (three samples were taken per year in the early phase). However, the fall 1984 sample had to be used because the study was not initiated until August of 1984.

Woody stem density.-Woody stems are the primary component of habitat structure within later sere old field habitat (Bazzaz 1990) and can have a strong impact on small mammal distribution (Dueser and Shugart 1978, Swihart and Slade 1990). Accordingly, we analyzed measures of stem density in addition to our vegetation cover estimates. However, there were no woody stem counts taken during 1984-1986 (there were very few woody stems present), therefore statistical comparisons of woody stem counts from the early and late successional phase were not possible (or necessary). We were able to qualitatively compare patterns of woody species establishment using data collected between 1990 and 1996. We statistically analyzed block size effects on the number of woody stems per quadrat using data from a portion of the late successional phase (1995 and 1996).

Plant community overlap.-The set of metrics described above bear on the effects of block size on gross (life form) measures of successional dynamics; however, individual plant species often have unique successional responses (e.g., Robinson et al. 1992, Bazzaz 1996, Halpern et al. 1997) and small mammal distribution can be influenced by specific plant species (Cockburn and Lidicker 1983). However, because addressing species-specific successional patterns is beyond the scope of this paper, we conducted a synoptic analysis of plant community similarity using individual plant species data as input for Horn's index of community overlap (HCO; Morisita 1959, Horn 1966, Wolda 1981). HCO was constructed using mean cover estimates of each species within each quadrat from 1985, 1986, 1994, and 1995. We generated HCO values for all pair-wise contrasts between block size (within each year) and across successional phase (resulting in 48 unique contrasts; see Table 3 for clarification).

\section{Small mammal measures}

In order to remove effects of different trapping protocols on comparisons between the two successional phases, raw trapping data were adjusted to a monthly, two-day trapping period. This yielded raw data sets with identical temporal structure and equal numbers of trapping periods within each season (winter: Decem- 
ber-February; spring: March-May; summer: June-August; fall: September-November).

Density.-Previous analyses of small mammal population abundance in our system were generated using a minimum number known alive (MNKA) index adjusted by trap density within each block size. However, in the analyses presented here and in Diffendorfer (1998), a Jolly-Seber method (Jolly 1965, Seber 1973) is used to estimate population size. This was done for two reasons. First, a small proportion of animals move between blocks on our study site within a trapping period (Diffendorfer et al. 1995a), violating assumptions in closed estimation models (e.g., MNKA, CAPTURE; White et al. 1982). Jolly-Seber is an open model allowing immigration and emigration. Second, JollySeber (unlike MNKA) uses probability of capture in estimating population size, so differences in capture probabilities across blocks are accounted for and no trap density adjustment is needed (Nichols and Pollock 1983, Manly 1984, Nichols 1992).

Our previous analyses also assumed that patch habitat was the only area used by small mammals. Interstitial area was assumed to be a completely hostile matrix and this area was not incorporated into any of our density estimation procedures (Foster and Gaines 1991, Gaines et al. 1992a, b, Diffendorfer et al. 1995a, $b$, 1996). However, recent evidence (Schweiger 1998, Wilson 1998; J. Foster, personal communication; R. Anderson and W. Schweiger, unpublished data) suggests that certain small mammal species use interstitial habitat for foraging and even nesting and that densities calculated using only patch area may be inflated. Accordingly, in our analyses here, we use simple rules (presented in Schweiger 1998) to more accurately estimate density across block size. The rules reflect species-specific estimates of the "effective" habitat used by each species.

Proportion of captures per trap.-Simultaneous examinations of responses to habitat heterogeneity at a variety of spatial scales may be necessary for a full understanding of the spatial ecology of small mammals (Morris 1987, 1989, Ims 1995, Dooley and Bowers 1996, Schweiger et al. 1999). Small mammals respond to variation in vegetative structure or composition via shifts in space use across multiple scales (Dueser et al. 1988, Rosenzweig 1989, Hanski 1990). Therefore, we also compared differences in the fine-scale distributions of each small mammal species across successional phase using the proportion of captures at each trap station for each species. Proportions were calculated at each trap as the number of captures in the trap during a successional phase, divided by the total number of captures across all traps within the phase. To avoid problems of dependence in this measure (e.g., repeat captures of the same individual; Hurlbert 1984), only the first capture of each individual was used (see also Kelt et al. 1994).

\section{Statistical design}

Most analyses of small mammal density and plant metrics used univariate general linear models (GLM) with block size, successional phase, and season (small mammal comparisons) or year (plant contrasts) nested within successional phase as independent variables. Season (or year) was nested within phase because each season (or year) was unique to the successional phase in which it occurred and could not be treated as a fixed effect common to both phases (e.g., the fall of 1985 only occurred in the early phase; Damon and Harvey 1987). The only interaction assumed meaningful was between block size and phase. Block size, season (or year) nested within phase, and the interaction between phase and block were tested over the error term in each model. However, the successional phase main level was tested over the sequential mean square of season (or year) nested within successional phase to account for the inclusion of season (or year) effects in the main level phase term. We altered our basic design for tests of white-footed mouse density and woody stem counts. We used GLMs with block size as a fixed effect and season (or year) as a random effect. Because these features were present only in trace amounts (if at all) during 1984-1987 we could not include any term for successional phase. Expected mean squares for all models were developed using Damon and Harvey (1987) and Sokal and Rohlf (1994).

In order to test for successional and block size effects on plant community overlap, HCO scores were grouped by two factors. First, we classified HCO scores by whether they contrasted plant communities within the same successional phase or across the two phases. Second, scores were grouped by the degree of similarity in block size from which the species cover data used to calculate the HCO score originated. These classes included contrasts within the same block size category (e.g., small vs. small), contrasts between block sizes separated by one size class (small vs. medium or medium vs. large), and contrasts between block size categories separated by two size classes (small vs. large). We then constructed a GLM model with successional phase as a main level term and the degree of similarity in block size from which each $\mathrm{HCO}$ score was generated as a covariate. Finally, we tested the interaction between successional phase and the block size similarity covariate.

To test the changes in the proportion of captures of each small mammal species we compared the spatial distributions of these proportions across successional phase using a spatially explicit generalization of the Cramer-von Mises (C-vM) test. For details of the calculation of the C-vM statistic see Syrjala (1996) and Zimmerman (1993). The C-vM statistic is sensitive to changes in the distribution and magnitude of the proportion of captures at each trap station (Conover 1980, Syrjala 1996). To establish the significance of the C- 
TABLE 1. Mean vegetative cover and woody stem counts by phase and block size.

\begin{tabular}{|c|c|c|c|c|c|c|c|c|}
\hline \multirow{3}{*}{$\begin{array}{l}\text { Block } \\
\text { size }\end{array}$} & \multirow{2}{*}{\multicolumn{2}{|c|}{ Woody cover $\left(\mathrm{cm}^{2}\right)$}} & \multirow{2}{*}{\multicolumn{2}{|c|}{$\begin{array}{l}\text { Woody stem counts } \\
\text { (no. per } 4 \times 4 \mathrm{~m} \\
\text { quadrat) }\end{array}$}} & \multirow{2}{*}{\multicolumn{2}{|c|}{ Grass cover $\left(\mathrm{cm}^{2}\right)$}} & \multirow{2}{*}{\multicolumn{2}{|c|}{ Forb cover $\left(\mathrm{cm}^{2}\right)$}} \\
\hline & & & & & & & & \\
\hline & Early phase & Late phase & phase & Late phase & Early phase & Late phase & Early phase & Late phase \\
\hline Small & $0.21(0.102)$ & $39.36(2.690)$ & $\ldots$ & $68.20(6.82)$ & $31.44(2.570)$ & $24.10(2.020)$ & $95.55(2.770)$ & $59.97(2.340)$ \\
\hline Medium & $0.04(0.042)$ & $29.13(3.170)$ & $\ldots$ & $73.78(6.57)$ & $23.83(2.730)$ & $23.02(2.600)$ & $111.53(4.490)$ & $66.33(2.520)$ \\
\hline Large & $0.24(0.082)$ & $32.08(2.690)$ & $\ldots$ & $96.52(9.13)$ & $30.36(2.850)$ & $16.62(1.910)$ & $101.55(3.030)$ & 74.13 (1.980) \\
\hline
\end{tabular}

Notes: Life-form cover estimates were collected each year from $1 \times 1 \mathrm{~m}$ quadrats and averaged across the three years within each successional phase (large block, $n=270$; medium block, $n=144$; small block, $n=240$ ). Because species cover estimates were summed within each life-form class, values may exceed $100 \mathrm{~cm}^{2}$. Woody stem counts were averaged over 1995 and 1996 data collected from $4 \times 4$ m quadrats $(n=180$ for large blocks, 96 for medium blocks, and 160 for small blocks) and include all woody species.

vM score for each comparison, we generated a distribution of C-vM test scores using a Monte Carlo algorithm. The algorithm calculated the value of the test statistic for all $2^{n}$ pairwise permutations of the data set ( $n=$ number of sampling locations). Because the number of possible permutations was unrealistic (e.g., with 280 trap stations, there are $1.9 \times 10^{84}$ possible values), we limited the protocol to 1000 iterations. The level of significance the C-vM scores generated for each comparison was determined by its position in this ordered set of 1000 test values. Finally, to assist in our interpretations of differences in fine-scale patterning in small mammal abundance, we calculated and plotted the difference across phase in the proportion of captures at each trap location.

All dependent variables in the GLMs were appropriately transformed (typically logarithm or square root) after being tested for normality using a ShapiroWilks test and for homogeneity of variance with Bartlett and Levene's tests (Martin and Games 1977, Conover 1980, Sokal and Rohlf 1994). Residuals were checked for normality using a Komologorov-Smirnov test (Ryan and Joiner 1976). All GLMs with significant block effects were followed by post-hoc multiple comparisons of block size means using a conservative Spjotvoll-Stoline test (SS; similar to a Tukey's posthoc comparison, modified for unequal sample sizes; Spjotvoll and Stoline 1973). All GLM analyses were conducted in STATISTICA version 5.1 or MINITAB version 11.1 (Statistica 1994, Minitab 1996). Our calculations of the C-vM statistics and the test score distributions were conducted with programs kindly provided by S. Syrjala.

\section{RESUlts}

Small mammal population abundance on our site (Diffendorfer et al. 1995a, b) and in many other systems (Hanski 1990 and references therein) can vary dramatically with season. In addition, old field plant succession can be rapid and episodic, with major changes in plant community composition over single growing seasons (Bazzaz 1996). Our models allowed us to determine when variance across successional phase exceeded within-phase variation (such as caused by seasonal effects). Therefore, when successional phase was significant we could conclude that differences in the two phases were not due to short-term fluctuations, even if there were significant season (or year) effects. This is because effects of season (or year) in the mean square of successional phase were controlled by testing over the nested term. Moreover, our tests of successional phase effects were conservative because of the reduced degrees of freedom associated with the nested season (or year) within successional phase term.

\section{Plants}

Forb cover.-Mean forb cover per quadrat averaged across all block sizes was lower in the late successional phase (Table 1). There were significant differences in mean forb cover among years within each phase (Table 2). During the late successional phase, mean forb cover varied with block size and was lower in small blocks (SS test; small vs. medium, $P=0.004$, small vs. large, $P<0.001)$. The decrease in forb cover was not consistent across block size as succession progressed, resulting in a block size by phase interaction (forb cover decreased by $73 \%$ in large, $59 \%$ in medium, and $62 \%$ in small blocks).

Grass cover.-Grass cover per quadrat averaged over all block sizes was not different in the two phases (Table 1). However, there were significant differences in mean grass cover among years within each phase (Table 2). For example, a cool wet spring in 1996 increased grass cover by on average $300 \%$ in each quadrat over 1994 and 1995 values. If 1996 data are excluded from the GLM, mean grass cover per quadrat was significantly lower in the late phase than in the early phase. There was a block size effect on grass cover in the late phase, with higher mean grass cover in small and medium blocks than in large blocks (SS test; $P<0.001$, large vs. small; $P=0.012$, large vs. medium). If 1996 data are excluded, the higher grass cover in smaller block is even more pronounced. There was a significant interaction between successional phase and block size. Mean grass cover per quadrat 
TABLE 2. General linear models of vegetative cover by successional phase, block size, the interaction between successional phase and block size, and year nested within successional phase.

\begin{tabular}{|c|c|c|c|c|c|c|c|c|c|c|}
\hline \multirow[b]{2}{*}{ Source } & \multirow[b]{2}{*}{ df } & \multicolumn{3}{|c|}{ Woody cover } & \multicolumn{3}{|c|}{ Grass cover } & \multicolumn{3}{|c|}{ Forb cover } \\
\hline & & MS & $F$ & $P$ & MS & $F$ & $P$ & MS & $F$ & $P$ \\
\hline Successional phase & 1 & 5826.66 & 41.75 & $<0.001$ & 270.42 & 0.48 & 0.406 & 1139.77 & 8.32 & 0.008 \\
\hline Block size & 2 & 40.86 & 6.22 & 0.002 & 115.3 & 12.49 & $<0.001$ & 57.82 & 11.66 & $<0.001$ \\
\hline $\begin{array}{l}\text { Successional phase } \times \\
\text { Block size }\end{array}$ & 2 & 39.19 & 5.97 & 0.003 & 101.42 & 10.99 & $<0.001$ & 31.37 & 6.33 & 0.002 \\
\hline $\begin{array}{l}\text { Year(Successional } \\
\text { phase) }\end{array}$ & 4 & 139.56 & 21.25 & $<0.001$ & 560.44 & 60.72 & $<0.001$ & 137.00 & 27.63 & $<0.001$ \\
\hline Error & 1295 & 6.57 & & & 9.23 & & & 4.96 & & \\
\hline Total & 1304 & & & & & & & & & \\
\hline
\end{tabular}

Notes: All dependent variables were square-root transformed prior to analysis. Significant contrasts are detailed in the Results section.

was largely unchanged across successional phase in medium blocks but decreased by $28 \%$ and $56 \%$ in small blocks and large blocks, respectively.

Woody cover and stem counts.-Woody cover dramatically increased over time within each block size (Table 1). There were significant differences in mean woody cover among years within phase, with increased woody cover during each successive year (Table 2). In addition, there was a block size effect on woody cover in the late successional phase, with slightly higher mean woody cover per quadrat in small blocks than in medium or large blocks (SS test; $P=0.013$, small vs. medium; $P=0.016$, small vs. large). Finally, because woody cover did not increase equally across all block sizes, there was a significant interaction between block size and successional phase.

In 1990,190 woody stems $>0.5 \mathrm{~m}$ in height were recorded in all 452 quadrats (including the seven blocks on the east half of the grid). By 1996, the number of woody stems $>0.5 \mathrm{~m}$ across all quadrats had increased to 17080 . From these quantities we estimate (assuming a linear relationship between stem count and patch area) that there were $\sim 990$ woody stems $>0.5 \mathrm{~m}$ tall across the entire site in 1990. This increased to an estimated 89000 stems in 1996, or an increase of al- most 90 woody stems per unit patch area. While we do not have any data on the numbers of woody stems $<0.5 \mathrm{~m}$ in height before 1994, we expect that the increase in woody seedlings per unit area with successional phase was even more dramatic (Yao et al. 1999).

In 1995 and 1996, woody stem counts (all species) per quadrat varied by block size $(\mathrm{df}=2,239, F=$ $3.88, P=0.022$; Table 1$)$. There were on average 28 more woody stems per quadrat in large blocks than in small blocks (SS test, $P=0.004$ ). Separate models of all species combined, tree species (bushy, stem-rich species such Rubus sp., Toxicodendron radicans, and Symphoricarpus orbiculatus excluded), and individual dominant woody species produced similar patterns across block size.

Plant community similarity.-Estimates of plant community overlap (HCO) within a successional phase were three to four times those computed for contrasts across successional phase (Table 3). Few plant species occurred in both phases. Those that were common to each phase typically had marked differences in mean cover per quadrat. The results from the GLM support these general conclusions, indicating that vegetation communities in successive years were more similar than communities separated by a decade ( $\mathrm{df}=1,36$,

TABLE 3. Horn's Index of plant community overlap by block size and year.

\begin{tabular}{|c|c|c|c|c|c|c|c|c|c|c|c|c|c|}
\hline \multirow[b]{2}{*}{ Year } & \multirow{2}{*}{$\begin{array}{c}\text { Block } \\
\text { size }\end{array}$} & \multicolumn{3}{|c|}{1995} & \multicolumn{3}{|c|}{1994} & \multicolumn{3}{|c|}{1986} & \multicolumn{3}{|c|}{1985} \\
\hline & & $S$ & $\mathrm{M}$ & $\mathrm{L}$ & $S$ & $\mathrm{M}$ & $\mathrm{L}$ & $S$ & $\mathrm{M}$ & $\mathrm{L}$ & $S$ & M & $\mathrm{L}$ \\
\hline \multirow[t]{3}{*}{1995} & $S$ & $\ldots$ & $\ldots$ & $\ldots$ & & & & & & & & & \\
\hline & M & 0.867 & $\ldots$ & $\ldots$ & & & & & & & & & \\
\hline & $\mathrm{L}$ & 0.856 & 0.882 & $\ldots$ & & & & & & & & & \\
\hline \multirow[t]{3}{*}{1994} & S & 0.907 & $\ldots$ & $\ldots$ & $\ldots$ & $\ldots$ & $\ldots$ & & & & & & \\
\hline & M & 0.836 & 0.915 & $\ldots$ & 0.899 & $\ldots$ & $\ldots$ & & & & & & \\
\hline & $\mathrm{L}$ & 0.824 & 0.861 & 0.913 & 0.855 & 0.867 & $\ldots$ & & & & & & \\
\hline \multirow[t]{3}{*}{1986} & $\mathrm{~S}$ & 0.262 & $\cdots$ & $\ldots$ & 0.252 & $\ldots$ & $\ldots$ & $\ldots$ & $\ldots$ & $\ldots$ & & & \\
\hline & M & 0.334 & 0.361 & $\ldots$ & 0.284 & 0.316 & $\ldots$ & 0.891 & $\ldots$ & $\ldots$ & & & \\
\hline & $\mathrm{L}$ & 0.292 & 0.324 & 0.318 & 0.287 & 0.311 & 0.297 & 0.932 & 0.918 & $\ldots$ & & & \\
\hline \multirow[t]{3}{*}{1985} & $\mathrm{~S}$ & 0.194 & $\ldots$ & $\ldots$ & 0.163 & $\ldots$ & $\ldots$ & 0.835 & $\ldots$ & $\ldots$ & $\ldots$ & $\ldots$ & $\ldots$ \\
\hline & M & 0.251 & 0.292 & $\ldots$ & 0.191 & 0.239 & $\ldots$ & 0.733 & 0.692 & $\ldots$ & 0.838 & $\ldots$ & $\ldots$ \\
\hline & $\mathrm{L}$ & 0.216 & 0.228 & 0.224 & 0.202 & 0.197 & 0.209 & 0.804 & 0.713 & 0.764 & 0.897 & 0.921 & $\ldots$ \\
\hline
\end{tabular}

Notes: S, M, and L, denote small, medium, and large, respectively. Horn's index ranges from 0 to 1.0 , with 1.0 indicating more similar communities. Values from comparisons across successional phase are shown in bold type. Significant contrasts are detailed in the Results section. 
$F=1445.1, P<0.001)$. However, the degree of similarity in block size did not strongly affect overlap in plant community composition, nor was there a significant interaction between successional phase and the covariate block size term (similar results were found using non-parametric Kruskal-Wallis tests, conducted as validation of the GLM).

\section{Mammals}

Prairie vole density and distribution.-Mean prairie vole density was influenced by successional phase, block size, and season (Fig. 2a; Table 4). The density of prairie voles in 1984-1986 was roughly half their 1994-1996 density (mean [1 SE] $=36.29$ [2.95] vs. 59.23 [3.65] animals/ha). Mean vole densities in the early phase were highest on large blocks (SS test; $P<$ 0.001 , for large vs. small; $P=0.042$, large vs. medium), whereas they were highest on small blocks in the late phase (SS test; $P<0.001$ for both small vs. large and small vs. medium). The magnitude of the increase in density with successional phase differed across block size, resulting in a significant interaction between successional phase and block size. Mean density increased on small blocks by 58 animals/ha (192\%), yet by only eight $(22 \%)$ and three $(7 \%)$ animals/ha in medium and large blocks, respectively (Fig. 2a). In each year of both phases, highest vole densities occurred during late fall.

There was a marginal difference in the distributions of the proportion of vole captures per trap across successional phase (mean C-vM statistic $=0.32, P=$ 0.0870 ), perhaps because of more captures on small blocks in the late successional phase relative to the early successional phase (Fig. 2b). Positive and negative changes in the proportion of captures per trap of voles in large and medium blocks were roughly equivalent (see also Schweiger et al. 1999).

Deer mouse density and distribution.-Mean deer mouse density was influenced by successional phase, block size, and season (Fig. 3a; Table 4). Deer mouse density was higher in the early phase (mean [1 $\mathrm{SE}]=$ 7.06 [0.64] in 1984-1986 vs. 2.39 [0.32] animals/ha in 1994-1996). In the early phase, densities were highest on small and large blocks (SS test; $P=0.017$ for large vs. medium blocks), while in the late phase, densities differed across all block sizes, with the highest densities on large blocks and lowest on small blocks (SS test; $P<0.001$ for both large vs. small and large vs. medium blocks, $P=0.013$ for medium vs. small blocks). There was a significant interaction between successional phase and block size, indicating that the decrease in deer mouse density with successional phase was not consistent across block size. Mean density on small blocks decreased by 7 animals/ha (94\%), with smaller decreases on medium (mean of 4 animals/ha, or $69 \%$ ) and large blocks (mean of 4 animals/ha, or $60 \%$ ). Finally, density peaked during late fall and early winter of all years within each phase.
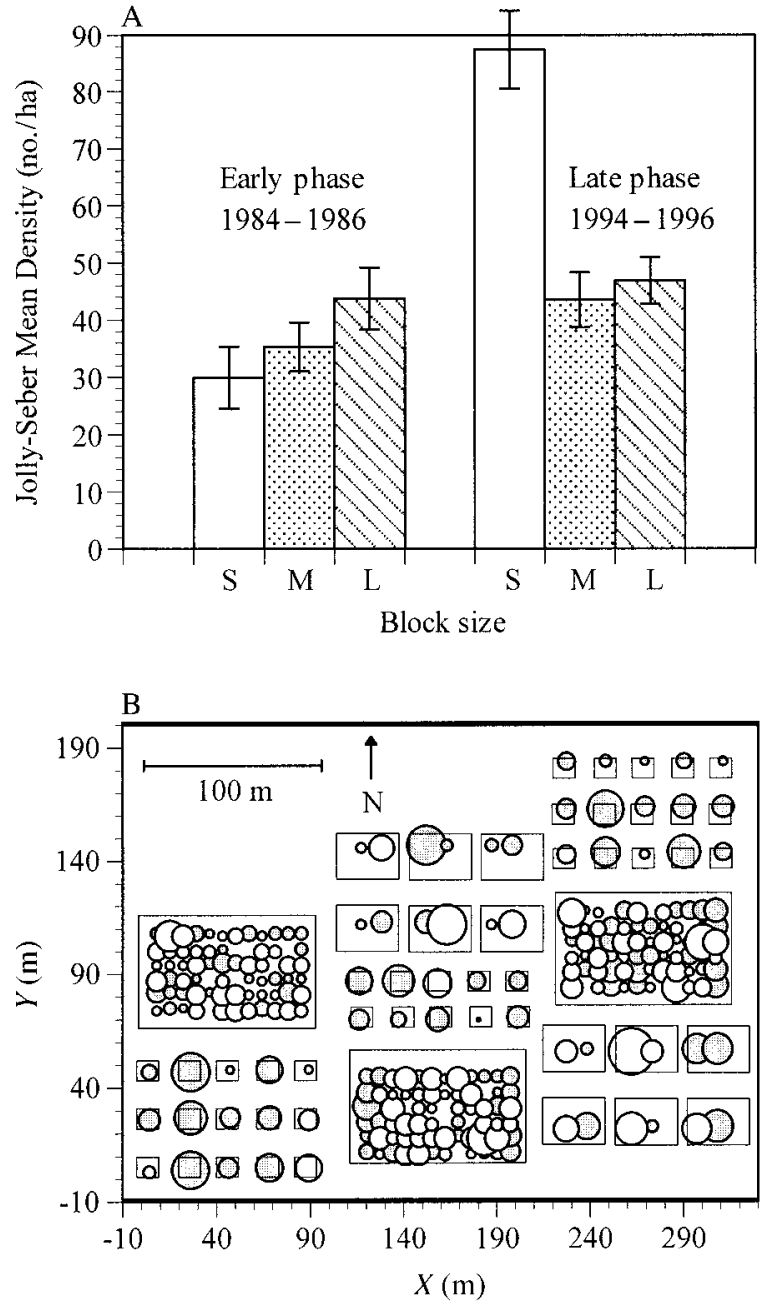

Decrease in $\%$ of captures per trap:

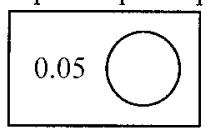

Increase in $\%$ of captures per trap:

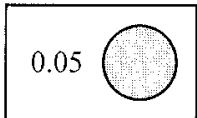

FIG. 2. (A) Mean ( $\pm 1 \mathrm{SE})$ Jolly-Seber prairie vole density (numbers per hectare) by block size and successional phase. All means were calculated from the 36 trapping sessions in each successional phase. Significant contrasts are detailed in the Results section. (B) Difference across successional phase in the proportion of prairie vole captures at each trapping station. The difference is proportional to the diameter of the circle centered on each trap location. Solid circles correspond to increases in probability of capture from the early successional phase to the late successional phase, while empty circles represent decreases. Patch dimensions, relative positions, and trap locations are approximate.

The distributions of the proportion of deer mouse captures per trap varied with successional phase (mean $\mathrm{C}$-vM statistic $=1.32, P=0.0190)$. There was a widespread decrease in deer mouse capture probability in the small block and large block on the west side of the study area (Fig. 3b). However, capture probability of 
TABLE 4. General linear models of small mammal density by successional phase, block size, the interaction between successional phase and block size, and year-season nested within successional phase.

\begin{tabular}{|c|c|c|c|c|c|c|c|c|c|c|}
\hline \multirow[b]{2}{*}{ Source } & \multirow[b]{2}{*}{ df } & \multicolumn{3}{|c|}{ Prairie vole } & \multicolumn{3}{|c|}{ Deer mouse } & \multicolumn{3}{|c|}{ Cotton rat } \\
\hline & & MS & $F$ & $P$ & MS & $F$ & $P$ & MS & $F$ & $P$ \\
\hline Successional phase & 1 & 26075.4 & 5.06 & 0.016 & 840.95 & 7.71 & 0.004 & 94.83 & 0.156 & 0.922 \\
\hline Block size & 2 & 7130.9 & 15.01 & $<0.001$ & 241.29 & 15.39 & $<0.001$ & 1106.19 & 21.19 & $<0.001$ \\
\hline $\begin{array}{l}\text { Successional phase } \times \\
\text { Block size }\end{array}$ & 2 & 16455.2 & 34.65 & $<0.001$ & 72.58 & 4.63 & 0.011 & 590.58 & 11.31 & $<0.001$ \\
\hline $\begin{array}{l}\text { Season(Successional } \\
\text { phase) }\end{array}$ & 24 & 5148.6 & 10.84 & $<0.001$ & 109.09 & 6.96 & $<0.001$ & 607.03 & 11.63 & $<0.001$ \\
\hline Error & 189 & 474.9 & & & 15.68 & & & 52.21 & & \\
\hline Total & 218 & & & & & & & & & \\
\hline
\end{tabular}

Notes: All density values were square-root transformed prior to analysis. Significant contrasts are detailed in the Results section.

deer mice generally increased within the large block on the eastern edge, suggesting that the spatial pattern of changes in capture probabilities within block size was complex (Schweiger et al. 1999).

Cotton rat density and distribution.-Averaged across the entire site, cotton rat density was roughly equivalent in each successional phase (Fig. 4a, Table 4 , mean $[1 \mathrm{SE}]=4.0[0.84]$ and $6.13[1.29]$ animals/ ha in the early and late phases, respectively). However, block size had a unique impact on mean cotton rat densities in each successional phase. In the early phase there were no cotton rats on small blocks and very few on medium blocks. There were nearly ten times more animals/ha on large blocks than on medium or small blocks (SS test; $P<0.001$ for both large vs. small and large vs. medium). Cotton rat distribution across block size was more equitable in the late successional phase, with similar densities in medium and large blocks. In contrast to the early phase, there were captures of cotton rats in small blocks in the late phase; however, density was lower in small blocks relative to medium and large blocks (SS test; $P=0.002$ for large vs. small, $P<0.001$ medium vs. small). Density in medium blocks increased from the early phase to the late phase by a mean of 8 animals/ha (604\%) and from zero animals in the early successional phase to a mean of 2 animals/ha during the late phase. By contrast, mean cotton rat density decreased by $66 \%$ (4 animals/ha) in large blocks. Finally, during each successional phase, density fluctuated dramatically with season across all block sizes, with localized disappearances in the winter followed by peak densities in the late summer of most years.

Changes in the distribution of the proportion of cotton rat captures per trap largely mirrored patterns in mean density. Overall, the distributions differed between phases (mean $\mathrm{C}$-vM statistic $=2.59, P=0.001$ ). The proportion of captures increased in all trap stations in small blocks (although numerically, there were few trap stations in small blocks with captures) and in nearly all trap stations in medium blocks (Fig. 4b). By contrast, the proportion of captures in trap stations in large blocks decreased (especially those well within large block interiors).

White-footed mouse density and distribution.White footed-mouse density varied with block size during the late phase (Fig. 5a; $\mathrm{df}=2,93, F=8.12, P=$ 0.001 ), with highest densities in large blocks (SS test; $P<0.001$ for large vs. small, $P=0.004$ for large vs. medium). Season was also significant, with peaks in late winter and early spring ( $\mathrm{df}=12,93, F=3.10, P$ $=0.001$ ).

As with mean density, distributions of the proportion of white-footed mouse captures per trap was not compared across successional phase with the C-vM test. However, the distribution within the late phase (Fig. 5b) suggests that white-footed mice were captured primarily on large blocks, especially on the western and southern edge of the study site (blocks L1 and L2, Fig. 1).

\section{DISCUSSION}

Our results suggest that landscape features such as patch size can directly influence old field plant succession and therefore indirectly modify long-term dynamics of small mammals. We know of no other study that has jointly documented long-term changes in plant and consumer communities as a function of patch size.

\section{Patterns across block size and successional phase}

Vegetation.-General plant successional patterns within our system resemble those reported for other studies of old fields (Inouye et al. 1987, Myster and Pickett 1988, 1994, Tilman 1988, 1994, Bazzaz 1990, 1996, Omancini et al. 1995). It is clear that the vegetation in the two successional phases differs in many aspects, from broad measures of vegetation cover to indices of overlap in community composition. Our interpretations of the patterns in our data suggest more continuous (large) blocks of old field underwent succession from annual and perennial herbaceous vegetation to a community dominated by woody plant species more rapidly than smaller, more fragmented blocks.

Throughout the early phase of succession there was 

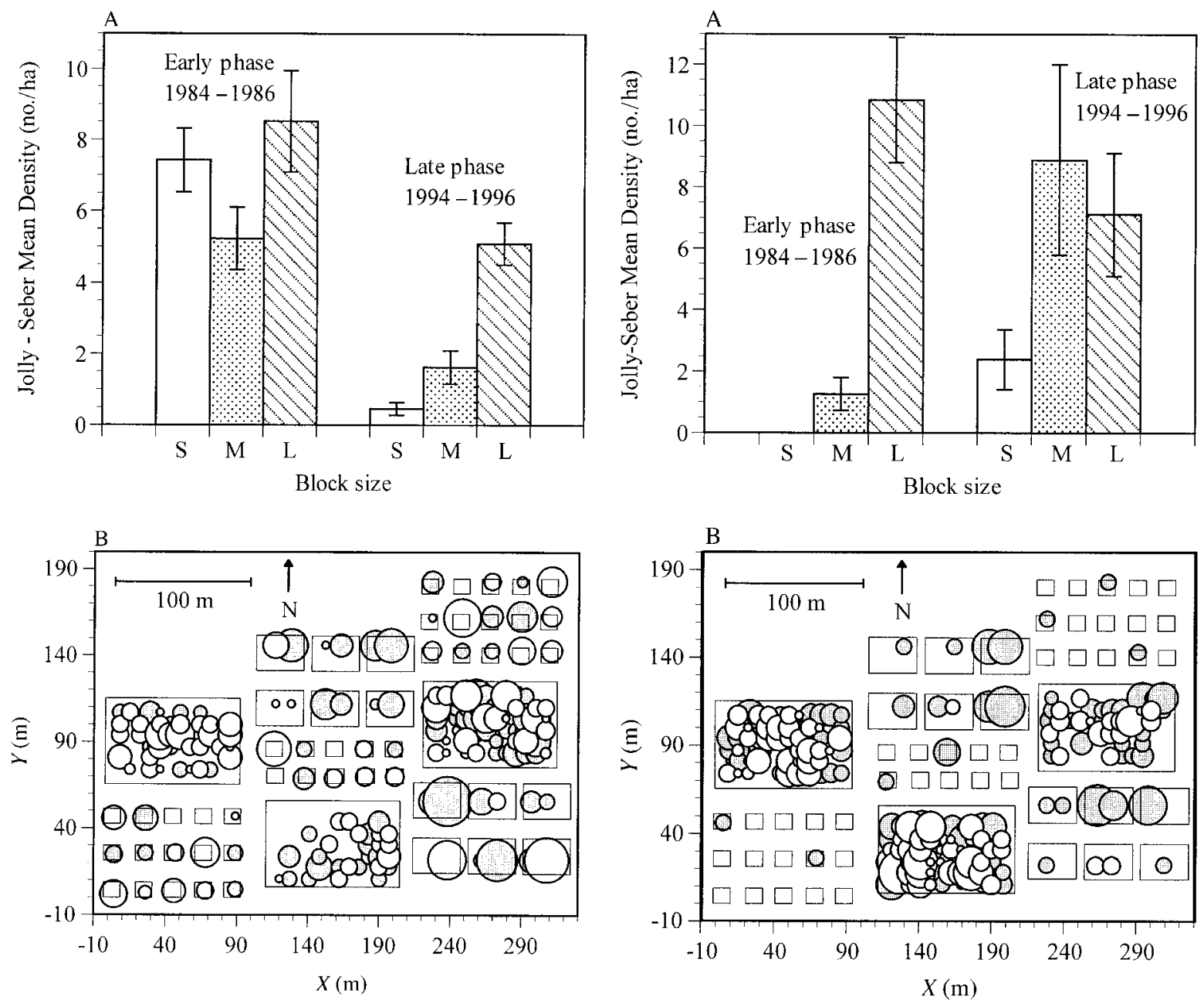

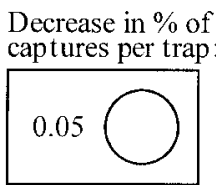

Increase in $\%$ of captures per trap:

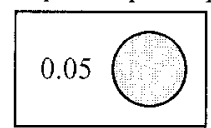

FIG. 3. (A) Mean ( \pm 1 SE) Jolly-Seber deer mouse density (numbers per hectare) by block size and successional phase. All means were calculated from the 36 trapping sessions in each successional phase. Significant contrasts are detailed in the Results section. (B) Difference across successional phase in the proportion of deer mice captured at each trapping station. The difference is proportional to the diameter of the circle centered on each trap location. Solid circles correspond to increases in probability of capture from the early successional phase to the late successional phase, while empty circles represent decreases. Patch dimensions, relative positions, and trap locations are approximate.

little difference across block size in either general (life form) or species-specific measures of plant cover, perhaps because many of the species in the earlier seres germinated from a seed bank, and distance and patch size effects on propagule dispersal were limited (Holt et al. 1995). With the colonization of woody species,
Decrease in $\%$ of captures per trap:

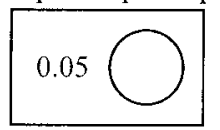

Increase in $\%$ of captures per trap:

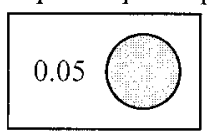

FIG. 4. (A) Mean ( \pm 1 SE) Jolly-Seber cotton rat density (numbers per hectare) by block size and successional phase. All means were calculated from the 36 trapping sessions in each successional phase. Significant contrasts are detailed in the Results section. (B) Difference across successional phase in the proportion of cotton rats captured at each trapping station. The difference is proportional to the diameter of the circle centered on each trap location. Solid circles correspond to increases in probability of capture from the early successional phase to the late successional phase, while empty circles represent decreases. Patch dimensions, relative positions, and trap locations are approximate.

structural complexity rapidly increased from 1990 to 1996, with considerable increases in the spatial variance (both vertical and horizontal) of woody stem heights and understory architecture. In contrast to the early phase, many features of the plant community were affected by block size once woody species had begun 

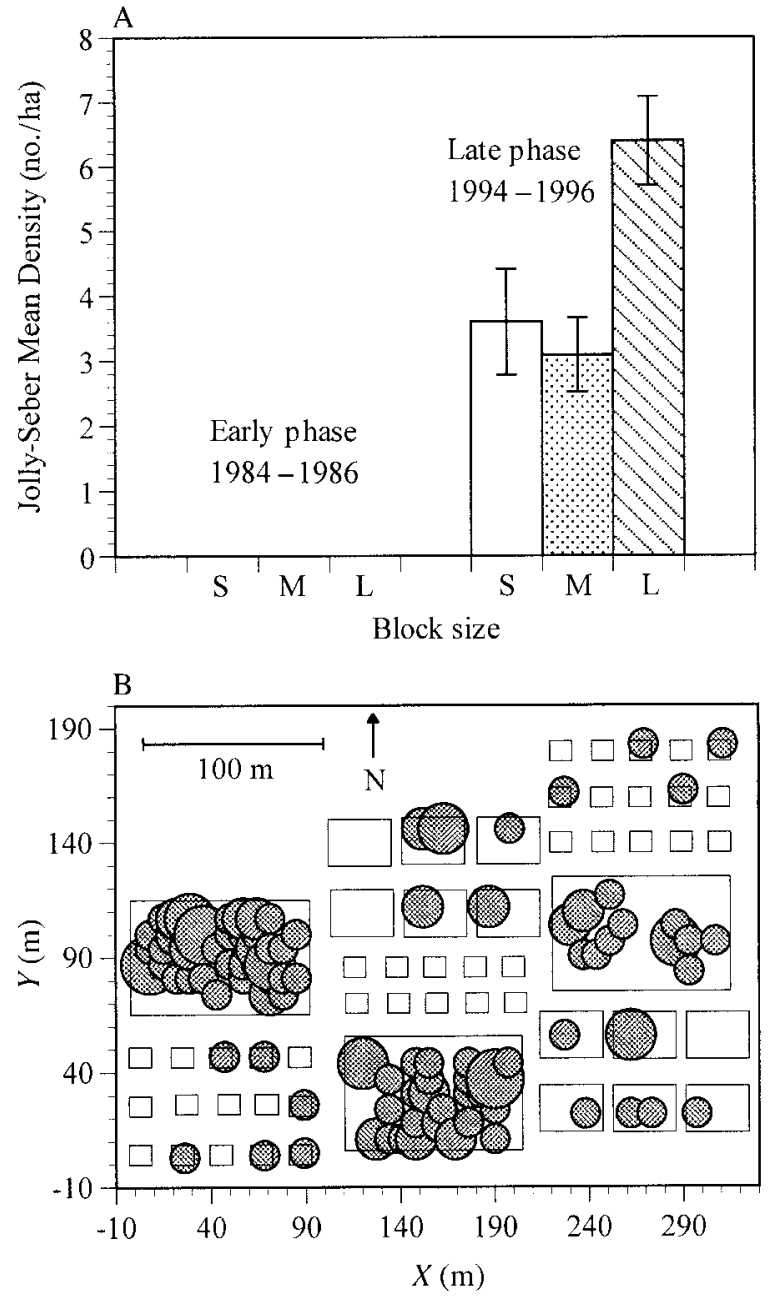

$\%$ of captures per trap:

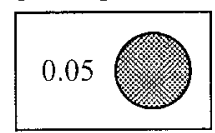

Fig. 5. (A) Mean ( \pm 1 SE) Jolly-Seber white-footed mouse density (numbers per hectare) by block size and successional phase. All means were calculated from the 36 trapping sessions in the late successional phase. Significant contrasts are detailed in the Results section. (B) Distribution of white-footed mouse proportion of captures per trap station during 1994-1996. Because there were no white-footed mouse captures during the early phase, the difference in the proportion of captures at each trap station could not be plotted. The value at each trap station is proportional to the diameter of the circle centered on the trap location. Patch dimensions, relative positions, and trap locations are approximate.

to dominate the system. Most notably, woody stem counts per quadrat were greatest on large blocks. Woody cover estimates per quadrat were higher on average in small blocks; however, we feel this reflects stem density affects on plant architecture rather than recruitment rates.

Most of the woody species found on the site in the late phase did not arise from the seed bank, but rather colonized from external sources. The accelerated rates of succession within large blocks may have been due to effects of patch area on woody species colonization and persistence. Large patches present bigger "targets" for woody plant seeds, enhancing rates of colonization (MacArthur and Wilson 1967, Schoener 1989, Phillips and Shure 1990). Larger patches also provide more sites of nucleation that are not spatially disconnected by fragmentation, facilitating the persistence of woody plant populations (Yarranton and Morrison 1974, Moody and Mack 1988). Beginning in 1994, block size also began to influence the cover of herbaceous species. The effect of block size on herbaceous species may have been indirect, via competition with overshadowing woody species that were directly influenced by block size (Holt 1984, Gill and Marks 1991, Wootton 1994, Holt et al. 1995). In short, “island”-like features may have become more evident within the system as succession proceeded (MacArthur and Wilson 1967, Schoener 1989, Holt et al. 1995).

Alternatively, small mammal herbivory and habitat modification may underlay many of the block size effects on the plant community seen in the late phase (Bowers and Dooley 1993, Ostfeld and Canham 1993, Jones et al.1994, Ostfeld et al. 1997). Recent analyses suggest that the magnitude of tree seedling predation by voles varies with block size (Schweiger 1998). Small mammals also create small-scale disturbances in old field habitat through nest and runway construction (Ostfeld et al. 1994). During the late successional phase, small and medium patches were riddled with vole runways, burrows, and burrow castings (Schweiger 1998). The cumulative effect of these disturbances on smaller blocks may have negatively impacted woody species recruitment (Moody and Mack 1988) and facilitated the persistence of early successional phase plant species adapted to disturbance (e.g., many annual grasses). These mechanisms are the focus of ongoing experimental work within the system.

Small mammals.-We hypothesized that long-term, directional change in the spatial patterning of each small mammal species would vary at the scales of our entire landscape and each block size. The dynamics of prairie voles, deer mice, and white-footed mice fit this general pattern. While changes in the density of cotton rats averaged across the entire site did not vary with successional phase, the effects of block size on mean density and capture distribution did change with time.

Relative preference for habitat features, including within patch attributes (vegetation composition) and patch size, coupled with agonistic interactions with other species (Foster and Gaines 1991, Gaines et al. 1992, Diffendorfer et al. 1996), appear to be the primary drivers of succession within the small mammal com- 
munity in our system. This explanation is essentially the habitat accommodation model of small mammal succession (Fox 1995), modified to include the effects of patch size on local habitat selection. Our empirical and statistical methods do not establish a mechanistic relationship between the habitat features we included in our analyses and successional changes in the small mammal community. Nevertheless, several of the patterns we observed are interpretable in light of the basic ecology of each species.

1. Prairie voles.-Prairie voles are typically found in habitats in eastern Kansas with relatively high cover of grasses and legumes (Brumwell 1951, Hansen and Warnock 1978, Cook et al. 1982, Getz 1985, Johnson and Gaines 1988, Marquis and Batzli 1989, Doonan 1993). The shift in prairie vole density and proportion of captures in each trap station towards small blocks with successional phase (Fig. 2a, b) may be in response to block size effects on plant succession. Slower plant succession within small blocks resulted in habitat better suited for prairie voles relative to the large blocks that experienced relatively quick succession and were dominated by woody plant species.

However, differences between small and medium blocks in grass cover in the late phase were small and nonexistent in the early phase. Therefore, if prairie vole abundance and distribution were responding to vegetation features alone, we would expect roughly equal vole densities across small and medium blocks in the late successional phase and across all block sizes in the early phase. This was not the case. In the early phase, successional change within the patch plant communities had not created sufficient cover for effective refugia from predation, especially in small blocks where succession was occurring more slowly (see also Harris 1988, Angelstam 1992, Laurance and Yensen 1995, Mills 1995, Donovan et al. 1997, Wolff et al. 1997). Voles reached their highest densities during the early phase on larger blocks, perhaps because there was sufficient patch area to counteract the lack of effective vegetative cover. By the late phase, increases in vegetation stature and heterogeneity had created adequate refugia across all block sizes. In small blocks, this cover was closely juxtaposed with interstitial areas, such that no point within a small patch was more than two meters from an edge. During the late phase the interstitial area contained plant species known to provide high quality forage for voles (i.e., Melilotus spp., Lespedeza spp., and Trifolium pratense; Marquis and Batzli 1989, Schweiger 1998). Thus, the high densities of voles on small blocks in the late phase may have resulted from close proximity of both cover from predators (Wilson 1998), and the ideal foraging areas in nearby interstitial habitat (see also Hyman et al. 1991, Lidicker et al. 1992). Other studies of old field small mammal communities indicate that voles prefer edges (Bowers et al. 1996, Dooley and Bowers 1996, Collins and Barrett 1997). In large, and to a lesser extent, me- dium blocks, the lower edge to interior ratios relative to small blocks may have limited the number of voles with high quality edge territories and prevented the dramatic demographic response seen in small blocks.

Alternatively, cotton rats (a behaviorally dominant competitor; Martin 1956, Frydenhall 1969, Terman 1978, Glass and Slade 1980, Prochaska and Slade 1981) may have limited vole distribution across block size. Earlier studies provide strong evidence of such competitive interactions within the system (Foster and Gaines 1991, Diffendorfer et al. 1995a, $b$, 1996). Cotton rats reached high mean densities in medium blocks in the late phase and may have limited the density of voles in these areas (which otherwise may have been adequate vole habitat). Nevertheless, despite increases in cotton rat density on medium blocks, vole abundance on medium blocks did not change between phases. It may be possible that increased competitive pressure from cotton rats was offset by increased quality of medium patches.

2. Deer mice.-Deer mice are one of the most common and widespread mammal species in North America, occurring in a wide variety of habitats (Baker 1968, Meserve 1976, Hansen and Warnock 1978, Terman 1978, Johnson and Gaines 1988). In eastern Kansas, deer mice prefer habitat with relatively high grass cover (Whitaker 1967). However, during the late phase, deer mice were rare in small and medium blocks where the highest mean cover of grass per quadrat was recorded. The virtual absence of deer mice from small blocks is opposite what we would predict if they were only responding to general successional patterns in the plant community within each block size.

Negative interactions with other small mammal species may have strongly affected the distribution of deer mice, excluding them from block sizes with a high coverage of their preferred forage. Vole density during the late phase on small blocks was such that during most trapping intervals each individual small patch was occupied by at least two animals. Therefore, any deer mouse living on a small block probably used the same runway network and encountered voles regularly (individual small patches are smaller than the mean home range size of both voles and deer mice; Diffendorfer et al. 1995b). Voles are competitively dominant to deer mice and can exclude them from areas which, based on vegetative characteristics alone, would be optimal deer mouse habitat (Grant 1971, Redfield et al. 1977, Abramsky et al. 1979). In addition, white-footed mice, another strong competitor of deer mice (Kaufman and Fleharty 1974), occurred in relatively high densities within the large blocks on the western (L2) and southern (L1) edges of the site (Fig. 1). Deer mouse capture proportions were low in these two blocks, yet increased on the eastern most large block (L3) where white-footed mice had yet to become well established (Figs. 1, 2b, 3b, and 5b; Schweiger et al. 1999).

Deer mice were captured in interstitial areas during 
both phases (see Schweiger 1998), suggesting that the nature of their response to fragmentation may differ from the other species on the grid. Deer mice may be capable of using all of the habitat types found on our site (mowed and successional areas), therefore block size may have been less important in influencing longterm patterns in deer mouse distributions (see Songer et al. 1997).

3. Cotton rats.-Cotton rats in eastern Kansas are typically associated with grassy habitat (Menhusen 1963, Fleharty and Olson 1969, Kaufman and Fleharty 1974, Carnes 1980, Swihart and Slade 1990, Randolph et al. 1991) and prefer thick vegetative cover (Goertz and Long 1973). Changes in cotton rat field-wide density across successional time displayed the only pattern that did not fit our original hypothesis. Increases in mean density on smaller blocks were offset by a decrease in large blocks. As plant succession on less fragmented large blocks reduced the cover of preferred cotton rat forage, densities declined and they shifted towards medium and small blocks where slower succession has retained a relatively high cover of palatable species. However, cotton rats are rarely found away from vegetative cover of some sort (especially in our system where they are the largest small mammal species and perhaps most susceptible to predation; Wilson 1998). Therefore, this shift in distribution (from large to smaller blocks) may have only been possible because of the increase in habitat heterogeneity afforded by woody stems on smaller blocks (see also Lidicker et al. 1992).

We expect that if patches continue to accumulate woody plant species and the understory (even in smaller patches) continues to move towards a community less and less dominated by early successional grass species, cotton rats will disappear from our site, or only persist in low numbers on small and medium blocks (see also Seamon and Adler 1996). Throughout 1996, cotton rats were largely restricted to medium blocks (mean $[1 \mathrm{SE}]=4.58$ [2.24] animals/ha) and occurred in very low densities on other block sizes ( $<1$ animal/ ha on both small and large blocks). During 1997, there were only 11 captures of cotton rats (six of which were on small and medium blocks), resulting in a mean density of $<1$ animal/ha, averaged across all block sizes.

4. White footed mice.-White-footed mice colonized our site during the late successional phase (1994). Therefore, we could not analyze these data using the same models as used on the other small mammal species. Nevertheless, the pattern of white-footed mouse colonization and their spatial distribution once they became established on the site may be the clearest example we have of the impact of habitat fragmentation on small mammal successional dynamics in our system.

During the late phase, white-footed mice reached their highest mean densities and had their highest proportion of captures per trap on large blocks (qualitatively; see Schweiger et al. 1999 for more detail), where woody plant species were most common due to more rapid plant succession (Fig. 5a, b). White-footed mice in eastern Kansas prefer habitats with high densities of woody stems and relatively closed canopies of woody vegetation (Baker 1968, Kaufman and Fleharty 1974, Batzli 1977, Hamilton and Whitaker 1979; see also Adler and Wilson 1987). Therefore, the bias in whitefooted mice distribution may have been in response to the species composition and structure of vegetation in large blocks.

However, several observations suggest that the colonization of our system by white-footed mice was influenced by more than just vegetation composition (see also Schweiger et al. 1999). Large blocks L1 and L2, both of which are immediately adjacent to continuous forest, had higher proportions of captures per trap than the eastern-most large block (L3), which was more distant from continuous forest (Figs. 1 and 5a, b). The small block in the southwest corner of the site, roughly the same distance from continuous forest as blocks L1 and L2 (favored by white-footed mice), had relatively low proportions of captures per trap. It appears that suitable habitat for white-footed mouse colonization may have only been available on large blocks immediately adjacent to continuous forest habitat. Thus, white-footed mice colonization was influenced by the interaction between block size, adjacency to the forest, and the extent of woody canopy development produced by vegetation succession.

Anecdotal data on eastern wood rats (Neotoma floridana; Wiley 1980), another woodland specialist small mammal, support our description of the factors important in white-footed mice colonization. Although too rare to analyze statistically (only 41 captures from 1994-1996), all captures (as well as all observations of middens) were on the two large blocks immediately adjacent to continuous forest (L1 and L2, Fig. 1).

\section{Caveats}

In general, we recognize that falsification of many of the mechanisms proposed here will require an experimental approach and investigation of behavioral interactions among species. Specifically, two caveats to our analyses and interpretations are worth noting.

First, alternate dependent variables such as survivorship, measures of reproductive performance, or proportion of a population consisting of resident animals (or multivariate combinations of such variables, e.g., Adler and Wilson 1987) may elucidate long-term dynamics that are inadequately described by density (van Horne 1983, Dooley and Bowers 1996). Measures of density often do not take into account social interactions that can decouple fitness and population density within a patch (Fretwell and Lucas 1970, Lidicker 1975, van Horne 1983; but see Morris 1987). Similarly, the woody, grass, and forb life form cover categories as well as the HCO similarity index encompass many individual plant species that may have specific influ- 
ences on small mammal behavior. Analyses of patterns in abundance or variance in the structure of specific plant species across block size may be more relevant than the general vegetative categories we utilized (Foster and Gaines 1991, Stokes 1994).

Second, the structure of our GLMs may not have decomposed temporal patterns in small mammal density or plant cover as effectively as a true repeat-measure model. Therefore, our dependent variables may be pseudoreplicated to some unknown degree. However, we feel that our use of the year-season (mammal) and year (plant) terms controls for some of this potential error and that the patterns we interpret are obvious enough that problems caused by pseudoreplication in our dependent variables would not alter our general conclusions. In addition, given sufficient environmental variability, animals are not likely to show linear responses to habitat features, and nonlinear statistical techniques may be most appropriate (Ruggiero et al. 1988, Wolff 1995, MacNally 1996).

\section{CONCLUSIONS}

Our results suggest that both direct and indirect effects of patch size influence succession of consumer communities within fragmented old fields. If vegetation in some habitat patches progresses through succession slower than in others, a greater variety of niches will exist within any patchy landscape than in a continuous landscape at any moment in time. Accordingly, fragmentation may indirectly facilitate the persistence of vagile consumer species within landscapes by creating heterogeneity in the rate at which patches progress through succession. On the other hand, fragmentation, by retarding the rate of old field plant succession, may delay colonization of consumer species that require more continuous patches of later successional vegetation.

Here, as in previous publications (Foster and Gaines 1991, Robinson et al. 1992, Holt et al. 1995, Diffendorfer et al. 1995a, $b, 1996$ ), patch size has been emphasized as the principal feature influencing the plant and small mammal community in our system. However, the composition, diversity, and spatial configuration of patch types, distances from sources (the forest and brome fields surrounding the site), edge-to-area ratios, and ecotonal features may also structure the plant and small mammal communities within the system (Lidicker 1995; see also Forman and Gordon 1986, Schweiger et al. 1999). Several of our interpretations of successional patterns in our system hint at the potential roles of such landscape-scale attributes.

Many studies have concluded that space has strong impacts on small mammal community composition and population dynamics. Spatial parameters such as patch size, intramatrix distances, and degree of patch isolation can influence how small mammal communities are structured (i.e., Abramsky et al. 1979, Glass and Slade 1980, Morris 1989, Harper et al. 1993, Danielson 1991,
Diffendorfer et al. 1996, Schweiger et al. 1999). The primacy of spatial effects as described within these studies, the vagility of small mammals, and the role of dispersal in their ecology suggests that the factors determining long term small mammal dynamics may include landscape features such as patch size that are not explicitly included in Fox's habitat accommodation model (Fox 1995). The model as originally proposed does not exclude landscape structure as one of the factors that might define a species niche and that species order within a successional sequence. However, our results suggest that future tests of the habitat accommodation model should explicitly include landscape features as possible explanatory factors driving patterns in small mammal succession. If ecologists hope to better understand the influence of landscape level effects on consumer succession, we will need to design experiments that can account for the influence of spatial heterogeneity at large and small scales on within-patch community dynamics.

\section{ACKNOWLEDGMENTS}

We would like to thank K. Armitage, D. Baldwin, M. Bowers, J. Foster, R. Peet, and N. Slade for helpful reviews of earlier drafts. G. Schlager and N. Slade assisted with the statistical analyses and C. Krebs and S. Syrjala graciously provided programs used in some of our computations. C. Welch, R. Anderson, and P. Wilson all shared their data. The personnel within P. Rich and K. Price's labs provided invaluable assistance with the GIS, especially P. Fu, R. O'Neal, and J. Black. Finally, none of our work would be possible without the tireless efforts of our field crews (Y. Alger, J. Foster, D. Heisler, B. Patrick, V. Peterson, J. Wang, J. Yao, and many others) and the maintenance personnel (B. Johanning and G. Pittman) at the Kansas Ecological Reserves. Our work has been supported by the National Science Foundation (BSR-8718089 and DEB-9308065), the General Research Fund, and the Experimental and Applied Ecology Program (both of the University of Kansas). Additional funding was provided to W. Schweiger from the American Museum of Natural History, American Society of Mammalogists, and Sigma Xi.

\section{Literature Cited}

Abramsky, Z., M. I. Dyer, and D. Harrison. 1979. Competition among small mammals in experimentally perturbed areas of short-grass prairie. Ecology 60:530-536.

Adler, G. H., and M. L. Wilson. 1987. Demography of a habitat generalist, the white-footed mouse, in a heterogeneous environment. Ecology 68:1785-1796.

Angelstam, P. 1992. Conservation of communities: the importance of edges, surroundings, and landscape mosaic structure. Pages 9-70 in L. Hansson, editor. Ecological principles of nature conservation. Elsevier, London, UK.

Atkeson, T. D., and A. S. Johnson. 1978. Succession of small mammals on pine plantations in the Georgia piedmont. American Midland Naturalist 10:385-392.

Baker, R. H. 1968. Habitats and distribution. Pages 98-126 in J. A. King, editor. Biology of Peromyscus (Rodentia). American Society of Mammalogists Publication Number 2. Lawrence, Kansas, USA.

Batzli, G. O. 1977. Population dynamics of the white-footed mouse in flood plain and upland forests. American Midland Naturalist 97:18-32.

Bazzaz, F. A. 1990. Plant-plant interactions in successional environments. Pages 239-263 in J. B. Grace and D. Tilman, 
editors. Perspectives on plant competition. Academic Press, New York, New York, USA.

Bazzaz, F. A. 1996. Plants in changing environments; linking physiological, population, and community ecology. Cambridge University Press, New York, New York, USA.

Bergeron, J. M., and L. Jodoin. 1987. Defining "high quality" food resources of herbivores: the case for meadow voles (Microtus pennsylvanicus). Oecologia 71:510-517.

Bowers, M. A., and J. L. Dooley. 1993. Predation hazard and seed removal by small mammals: microhabitat versus patch scale effects. Oecologia 94:247-254.

Bowers, M. A., K. Gregario, C. J. Brame, S. F. Matter, and J. L. Dooley. 1996. Use of space and habitats by meadow voles at the home range, patch, and landscape scales. Oecologia 105:107-115.

Brumwell, M. J. 1951. An ecological survey of the Fort Leavenworth Military Reservation. American Midland Naturalist 45:187-231.

Byers, R. E. 1985. Management and control. Pages 286-309 in R. H. Tamarin, editor. Biology of New World Microtus. American Society of Mammalogists Special Publications Number 8. Lawrence, Kansas, USA.

Carnes, B. A. 1980. Habitat selection in a prairie rodent community. Dissertation. University of Kansas, Lawrence, Kansas, USA.

Cockburn, A., and W. Z. Lidicker, Jr. 1983. Microhabitat heterogeneity and population ecology of a herbivorous rodent, Microtus californicus. Oecologia 59:167-177.

Collins, R. J., and G. W. Barrett. 1997. Effects of habitat fragmentation on meadow vole (Microtus pennsylvanicus) population dynamics in experimental landscape patches. Landscape Ecology 12:63-76.

Connell, J. H., and R. O. Slatyer. 1977. Mechanisms of succession in natural communities and their role in community stability and organization. American Naturalist 111:11191144.

Conover, W. J. 1980. Practical nonparametric statistics. Second edition. John Wiley \& Sons, New York, New York, USA.

Cook, J. C., M. S. Topping, and T. A. Stombaugh. 1982. Food habits of Microtus ochrogaster and Peromyscus maniculatus in sympatry. Transactions of the Missouri Academy of Sciences 16:17-24.

Damon, R. A., and W. R. Harvey. 1987. Experimental design, ANOVA, and regression. Harper and Row, New York, New York, USA.

Danielson, B. J. 1991. Communities in a landscape: the influence of habitat heterogeneity on the interactions between species. American Naturalist 138:1105-1120.

Davidson, D. W. 1993. The effects of herbivory and granivory on terrestrial plant succession. Oikos 68:23-35.

Diffendorfer, J. E. 1998. Testing models of source-sink dynamics and balanced dispersal. Oikos 81:417-433.

Diffendorfer, J. E., R. D. Holt, N. A. Slade, and M. S. Gaines. 1996. Small mammal community patterns in old fields; distinguishing site-specific from regional processes. Pages 421-467 in M. L. Cody and J. A. Smallwood, editors. Long-term studies of vertebrate communities. Academic Press, Orlando, Florida, USA.

Diffendorfer, J. E., N. A. Slade, M. S. Gaines, and R. D. Holt. 1995a. Habitat fragmentation and movements of three small mammals. Ecology 76:827-839.

Diffendorfer, J. E., N. A. Slade, M. S. Gaines, and R. D. Holt. 1995b. Population dynamics of small mammals in fragmented and continuous old field habitat. Pages 175-200 in W. Z. Lidicker, editor. Landscape approaches in mammalian ecology and conservation. University of Minnesota Press, Minneapolis, Minnesota, USA.

Donovan, T. M., P. W. Jones, E. M. Annand, and F. R. Thomp- son III. 1997. Variation in local-scale edge effects: mechanisms and landscape context. Ecology 78:2064-2075.

Dooley, J. L., and M. A. Bowers. 1996. Influences of patch size and microhabitat on the demography of two old field rodents. Oikos 75:453-462.

Doonan, T. J. 1993. Effects of an experimental increase in resource abundance on population dynamics and community structure in small mammals. Dissertation. University of Kansas, Lawrence, Kansas, USA.

Dueser, R. D., J. L. Dooley, and G. J. Taylor. 1988. Habitat structure, forest composition and landscape dimensions as components of habitat suitability for the Delmarva fox squirrel. Pages 414-421 in R. C. Szaro, K. E. Severson, and D. R. Patton, editors. Management of amphibians, reptiles and small mammals in North America. United States Department of Agriculture, General Technical Report RM166. Washington, D.C., USA.

Dueser, R. D., and H. H. Shugart. 1978. Microhabitats in a forest floor small mammal fauna. Ecology 59:89-98.

Egler, F. E. 1954. Vegetation science concepts. I. Initial floristic composition as a factor in old field vegetation development. Vegetatio 4:412-417.

Fleharty, E. D., and L. E. Olson. 1969. Summer food habits of Microtus ochrogaster and Sigmodon hispidus. Journal of Mammalogy 50:475-486.

Forman, R. T., and M. Gordon. 1986. Landscape ecology. Wiley and Sons, New York, New York, USA.

Foster, J., and M. S. Gaines. 1991. The effects of a successional habitat mosaic on a small mammal community. Ecology 72:1358-1373.

Fox, B. J. 1982. Fire and mammalian succession in an Australian coastal heath. Ecology 63:1332-1341.

Fox, B. J. 1990. Changes in the structure of mammal communities over successional time scales. Oikos 59:321-329.

Fox, B. J. 1995. Long-term studies of small-mammal communities from disturbed habitats in eastern Australia. Pages 467-501 in M. L. Cody and J. A. Smallwood, editors. Long term studies of vertebrate communities. Academic Press, Orlando, Florida, USA.

Fretwell, S. D., and H. L. Lucas. 1970. On territorial behavior and other factors influencing habitat distribution in birds. Acta Biotheoretica 19:16-36.

Frydenhall, M. J. 1969. Rodent populations in four habitats in central Kansas. Transactions of the Kansas Academy of Science 72:213-222.

Gaines, M. S., J. Foster, J. E. Diffendorfer, W. E. Sera, R. D. Holt, and G. R. Robinson. 1992a. Population processes and biological diversity. Transactions of the North American Wildlife and Natural Resources Conference 57:252262.

Gaines, M. S., G. R. Robinson, R. D. Holt, M. L. Johnson, and J. E. Diffendorfer. 1992b. The effects of habitat fragmentation on small mammal populations. Pages 875-885 in D. R. McCullough and R. H. Barrett, editors. Wildlife 2001: populations. Elsevier Press, New York, New York, USA.

Getz, L. L. 1985. Habitats. Pages 286-309 in R. H. Tamarin, editor. Biology of New World Microtus. Special Publication Number 8 of the American Society of Mammalogists. Lawrence, Kansas, USA.

Gill, D. S., and P. L. Marks. 1991. Tree and shrub seedling colonization of old fields in central New York. Ecological Monographs 61:183-205.

Glass, E. G., and N. A. Slade. 1980. The effect of Sigmodon hispidus on spatial and temporal activity of Microtus ochrogaster: evidence for competition. Ecology 61:358-370.

Gleason, H. A. 1928. The individualistic concept of the plant association. Bulletin of the Torrey Botanical Club 53:7-26.

Glenn-Lewin, D. C. 1980. The individualistic nature of plant community development. Vegetatio 42:141-146. 
Glenn-Lewin, D. C., R. K. Peet, and T. T. Veblen, editors. 1992. Plant succession: theory and prediction. Chapman and Hall, London, UK.

Goertz, J. W., and R. C. Long 1973. Habits of five species of rat in Louisiana. American Midland Naturalist 90:460465.

Goodall, D. W. 1952. Some consideration in the use of point quadrats for the analysis of vegetation. Australian Journal of Scientific Research Series B5:1-41.

Grant, P. R. 1971. Experimental studies of competitive interaction in a two-species system. Microtus and Peromyscus species in enclosures. Journal of Animal Ecology 40:323350 .

Great Plains Flora Association. 1986. Flora of the Great Plains. University of Kansas Press, Lawrence, Kansas, USA.

Halpern, C. B., J. A. Antos, M. A. Geyer, and A. M. Olson. 1997. Species replacement during early secondary succession: the abrupt decline of a winter annual. Ecology 78: 621-631.

Hamilton, W. J., and J. O. Whitaker. 1979. Mammals of the eastern United States. Cornell University Press, Ithaca, New York, USA.

Hansen, L. P., and J. E. Warnock. 1978. Response of two species of Peromyscus to vegetational succession on land strip-mined for coal. American Midland Naturalist 110: 177-185.

Hanski, I. 1990. Density dependence, regulation and variability in animal populations. Philosophical Transactions of the Royal Society of London 330:141-150.

Harper, J. P. 1977. Population biology of plants. Academic Press, New York, New York, USA.

Harper, S. J., E. K. Bollinger, and G. W. Barrett. 1993. The effects of habitat patch shape on population dynamics of meadow voles (Microtus pennsylvanicus). Journal of Mammalogy 74:1045-1055.

Harris, L. D. 1988. Edge effects and conservation of biotic diversity. Conservation Biology 2:330-332.

Holt, R. D. 1984. Spatial heterogeneity, indirect interactions and the coexistence of prey species. American Naturalist 124:377-406.

Holt, R. D., G. R. Robinson, and M. S. Gaines. 1995. Vegetation dynamics in an experimentally fragmented landscape. Ecology 76:1610-1624.

Horn, H. S. 1966. Measurement of "overlap" in comparative ecological studies. American Naturalist 100:419-424.

Huntly, N., and R. S. Inouye. 1987. Small mammal populations of an old field chronosequence: successional patterns and associations with vegetation. Journal of Mammalogy 68:739-745.

Hurlbert, S. H. 1984. Pseudoreplication and the design of field experiments. Ecological Monographs 54:187-211.

Hyman J. B., J. B. McAninch, and D. L. DeAngelis. 1991. An individual-based simulation model of herbivory in a heterogeneous landscape. Pages 443-475 in M. G. Turner and H. Gardener, editors. Quantitative methods in landscape ecology: the analysis and interpretation of landscape heterogeneity. Springer-Verlag, New York, New York, USA.

Ims, R. A. 1995. Movement patterns related to spatial structure. Pages 85-109 in L. Hansson, L. Fahrig, and G. Merriam, editors. Mosaic landscapes and ecological processes. Chapman and Hall, London, UK.

Inouye, R. S., N. J. Huntly, D. Tilman, J. R. Tester, M. A. Stillwell, and K. C. Zinnel. 1987. Old field succession on a Minnesota sand plain. Ecology 68:12-26.

Janzen, D. H. 1971. Seed predation by animals. Annual Review of Ecology and Systematics 2:465-492.

Johnson, M. L., and M. S. Gaines. 1988. Demography of the western harvest mouse, Reithrodontomys megalotis, in eastern Kansas. Oecologia 75:405-412.

Jolly, G. M. 1965. Explicit estimates from capture-recapture data with both death and immigration-stochastic model. Biometrika 52:225-247.

Jones, C. G., J. H. Lawton, and M. Shachak. 1994. Organisms as ecosystem engineers. Oikos 69:373-386.

Kareiva, P. M. 1987. Habitat fragmentation and the stability of predator-prey interactions. Nature 326:388-390.

Kareiva, P. M. 1990. Population dynamics in spatially complex environments: theory and data. Philosophical Transactions of the Royal Society of London 330:175-190.

Kaufman, D. W., and E. D. Fleharty. 1974. Habitat selection by nine species of rodents in north central Kansas. The Southwestern Naturalist 18:443-452.

Kelt, D. A., P. L. Meserve, and B. K. Lang. 1994. Quantitative habitat associations of small mammals in a temperate rain forest in southern Chile: empirical patterns and the importance of ecological scale. Journal of Mammalogy 75: 890-904.

Krohne, D. T. 1997. Dynamics of metapopulations of small mammals. Journal of Mammalogy 78:1014-1026.

Laurance, W. F., and E. Yensen. 1991. Predicting the impacts of edge effects in fragmented habitats. Biological Conservation 55:77-92.

Lavorel, S., R. V. O’Neill, and R. H. Gardner. 1994. Spatiotemporal dispersal strategies and annual plant species coexistence in a structured landscape. Oikos 71:75-88.

Lidicker, W. Z. 1975. The role of dispersal in the demography of small mammals. Pages 103-128 in F. B. Golley, K. Petusewicz, and L. Ryszkowski, editors. Small mammal dynamics: their productivity and population dynamics. Cambridge University Press, New York, New York, USA.

Lidicker, W. Z. 1995. The landscape context: Something old, something new. Pages 3-19 in W. Z. Lidicker, editor. Landscape approaches in mammalian ecology and conservation. University of Minnesota Press, Minneapolis, Minnesota, USA.

Lidicker, W. Z., J. O. Wolffe, L. N. Lidicker, and M. H. Smith. 1992. Utilization of a habitat mosaic by cotton rats during a population decline. Landscape Ecology 6:259-268.

MacArthur, R. H., and E. O. Wilson. 1967. The theory of island biogeography. Princeton University Press, Princeton, New Jersey, USA.

MacMahon, J. A. 1981. Successional processes: comparison among biomes with special reference to probable roles of and influences on animals. Pages 277-304 in D. C. West, H. H. Shugart, and D. B. Botkin, editors. Forest succession. Springer-Verlag, New York, New York, USA.

MacNally, R. 1996. Hierarchical partitioning as an interpretative tool in multivariate inference. Australian Journal of Ecology 21:224-228.

Manly, B. F. J. 1984. Obtaining confidence limits on parameters of the Jolly-Seber model for capture-recapture data. Biometrics 40:749-758.

Marquis, R. J., and G. O. Batzli. 1989. Influence of chemical factors on palatability of forage to voles. Journal of Mammalogy 70:503-511.

Martin, C. G., and P. A. Games. 1977. ANOVA tests for homogeneity of variance: nonnormality and unequal samples. Journal of Educational Statistics 2:187-206.

Martin, E. P. 1956. A population study of the prairie vole (Microtus ochrogaster) in northeastern Kansas. Museum of Natural History, University of Kansas. 8:361-416.

Menhusen, B. R. 1963. An investigation of the food habits of four species of rodents in captivity. Transactions of the Kansas Academy of Science 66:107-112.

Meserve, R. L. 1976. Foods relationships of a rodent fauna in a California coastal sage scrub community. Journal of Mammalogy 55:809-823. 
Mills, L. S. 1995. Edge effects and isolation: red-backed voles of forest remnants. Conservation Biology 9:395-403.

Minitab. 1996. Minitab Release 11. Minitab, State College, Pennsylvania, USA.

Moody, M. E., and R. N. Mack. 1988. Controlling the spread of plant invasions: the importance of nascent foci. Journal of Applied Ecology 25:1009-1021.

Morisita, M. 1959. Measuring interspecific association and similarity between communities. Memo of Faculty of Science, Kyushu University, Series E. (Biology) 3:65-80.

Morris, D. W. 1987. Ecological scale and habitat use. Ecology 68:362-369.

Morris, D. W. 1989. The effects of spatial scale on patterns of habitat use: red backed voles as an empirical model of local abundance for northern mammals. Pages 23-33 in D. W. Morris, Z. Abramsky, B. J. Fox, and M. R. Willig, editors. Patterns in the structure of mammalian communities. Special Publication Number 28 of the Museum of Texas Tech University, Lubbock, Texas, USA.

Myster, R. W., and S. T. A. Pickett. 1988. Individualistic pattern of annuals and biennials in early successional old fields. Vegetatio 78:53-60.

Myster, R. W., and S. T. A. Pickett. 1994. A comparison of succession over 18 years in 10 contrasting old fields. Ecology 75:387-392.

Nichols, J. D. 1992. Capture-recapture models. BioScience 42:94-102.

Nichols, J. D., and K. H. Pollock. 1983. Estimation methodology in contemporary small mammal capture-recapture studies. Journal of Mammalogy 64:253-260.

Omancini, M., E. J. Chaneton, R. C. Leon, and W. B. Baptista. 1995. Old field successional dynamics on the Inland Pampa, Argentina. Journal of Vegetation Science 6:309-316.

Ostfeld, R. S., and C. D. Canham. 1993. Effects of meadow vole population density on tree seedling survival in old fields. Ecology 74:1792-1801.

Ostfeld, R. S., N. Lewin, J. Schnurr, S. T. Pickett, and C. D. Canham. 1994. The roles of small mammals in creating patchy environments. Polish Ecological Society 20:265276.

Ostfeld, R. S., R. H. Manson, and C. D. Canham. 1997. Effects of rodents on survival of tree seeds and seedlings invading old fields. Ecology 78:1531-1542.

Pearson, P. G. 1959. Small mammals and old field succession on the piedmont of New Jersey. Ecology 40:249-253.

Phillips, D. L., and D. J. Shure. 1990. Patch size effects on early succession in southern Appalachian forests. Ecology 71:204-212.

Prochaska, S., and N. Slade 1981. The effect of Sigmodon hispidus on summer diel activity patterns of Microtus ochrogaster in Kansas. Transactions of the Kansas Academy of Sciences 84:134-138.

Pulliam, R. H. 1988. Sources, sinks and population regulation. American Naturalist 132:652-661.

Pulliam, R. H., and B. J. Danielson. 1992. Sources, sinks, and habitat selection: A landscape perspective on population dynamics. American Naturalist 137:50-66.

Randolph, J. C., G. N. Cameron, and J. A. Wrazen. 1991. Dietary choice of a generalist grassland herbivore Sigmodon hispidus. Journal of Mammalogy 72:300-313.

Raunkiaer, C. 1934. The life forms of plants and statistical plant geography. Clarendon Press, Oxford, UK.

Redfield, J. A., C. J. Krebs, and M. J. Taitt. 1977. Competition between Peromyscus maniculatus and Microtus townsendii in grasslands of coastal British Colombia. Journal of Animal Ecology 46:607-616.

Robinson, G. R., R. D. Holt, M. S. Gaines, S. P. Hamburg, M. L. Johnson, H. S. Fitch, and E. A. Martinko. 1992. Diverse and contrasting effects of habitat fragmentation. Science 257:524-526.
Rosenzweig, M. L. 1989. Habitat selection, community organization, and small mammal studies. Pages 5-23 in D. W. Morris, Z. Abramsky, B. J. Fox, and M. R. Willig, editors. Patterns in the structure of mammalian communities. Special Publication Number 28 of the Museum of Texas Tech University, Lubbock, Texas, USA.

Ruggiero, L. F., K. B. Aubry, R. S. Holthausen, J. W. Thomas, B. G. Marcott, and E. C. Meslow. 1988. Ecological dependency: the concept and its implications for research and management. Pages 112-126 in R. E. McCabe, editor. Transactions of the 53rd North American Wildlife and Natural Resource Conference. Wildlife Management Institute, Washington D.C., USA.

Ryan, T. A., Jr., and B. L. Joiner. 1976. Normal probability plots and tests for normality. Technical Report, Statistics Department, Pennsylvania State University, State College, Pennsylvania, USA.

Saunders, D. A., R. J. Hobbs, and C. R. Margules. 1991. Biological consequences of ecosystem fragmentation: a review. Conservation Biology 2:340-347.

Schoener, A. 1989. Experimental biogeography. Pages 483512 in P. S. Giller, editor. Analytical biogeography. Chapman and Hall, London, UK.

Schupp, E. W. 1988. Seed and early seedling predation in the forest understory and in treefall gaps. Oikos 51:71-78.

Schweiger, E. W. 1998. The interaction of habitat fragmentation, plant, and small mammal succession in an old field: patterns and mechanisms. Dissertation. University of Kansas, Lawrence, Kansas, USA.

Schweiger, E. W., R. Holt, R. Pierotti, and J. Diffendorfer. 1999. The relative importance of small-scale and landscape-level heterogeneity in structuring small mammal distributions. Pages 175-207 in G. Barrett and J. Peles, editors. Landscape ecology of small mammals. Springer-Verlag, New York, New York, USA.

Seamon, J. O., and G. H. Adler. 1996. Population performance of generalist and specialist rodents along habitat gradients. Canadian Journal of Zoology 74:1130-1139.

Seber, G. A. F. 1973. The estimation of animal abundance and related parameters. Griffin, London, UK.

Sietman, B. E., W. B. Fothergill, and E. J. Finck. 1994. Effects of haying and old field succession on small mammals in tall grass prairie. American Midland Naturalist 131:1-18.

Simberloff, D. 1988. The contribution of population and community biology to conservation science. Annual Review of Ecology and Systematics 19:473-511.

Sly, G. R. 1976. Small mammal succession on strip mined land in Vigo County, Indiana. American Midland Naturalist 95:257-267.

Sokal, R., and F. J. Rohlf. 1994. Biometry. W. H. Freeman and Company, New York, New York, USA.

Songer, M. A., M. V. Lomolino, and D. R. Perault. 1997. Niche dynamics of deer mice in a fragmented, old-growth landscape. Journal of Mammalogy 78:1027-1039.

Soule, M. 1986. Conservation biology. Sinauer Associates, Sunderland, Massachusetts, USA.

Soule, M. E., A. C. Alberts, and D. T. Bolger. 1992. The effects of habitat fragmentation on chaparral plants and vertebrates. Oikos 63:39-47.

Spjotvoll, E., and M. R. Stoline. 1973. An extension of the T-method of multiple comparison to include cases with unequal sample sizes. Journal of the American Statistical Association 68:976-978.

Statistica. 1994. Version 5.1. Statsoft, Tulsa, Oklahoma, USA.

Stokes, M. K. 1994. Effects of weather and climate on populations of small mammals: implication for climatic change. Dissertation. University of Kansas, Lawrence, Kansas, USA.

Swihart, R. K., and N. A. Slade. 1985. Testing for indepen- 
dence of observations of animal movements. Ecology 66: 1176-1184.

Swihart, R. K., and N. A. Slade. 1990. Long-term dynamics of and early successional small mammal community. American Midland Naturalist 123:372-382.

Syrjala, S. E. 1996. A statistical test for a difference between the spatial distributions of two populations. Ecology 77: 75-80.

Terman, M. R. 1978. Population dynamics of Microtus ochrogaster and Sigmodon hispidus in central Kansas. Transactions of the Kansas Academy of Science 77:337-351.

Tilman, D. 1987. Secondary succession and the pattern of plant dominance along experimental nitrogen gradients. Ecological Monographs 57:189-214.

Tilman, D. 1988. Plant strategies and the dynamics and structure of plant communities. Princeton University Press, Princeton, New Jersey, USA.

Tilman, D. 1994. Competition and biodiversity in spatially structured habitats. Ecology 75:2-16.

Turner, I. M. 1996. Species loss in fragments of tropical rain forest: a review of the evidence. Journal of Applied Ecology 33:200-209.

Usher, M. B. 1987. Effects of fragmentation on communities and populations: a review with applications to wildlife conservation. Pages 103-121 in D. A. Saunders, G. W. Arnold, A. A. Burbudge, and A. J. M. Hopkins, editors. Nature conservation: the role of remnants of native vegetation. Surrey Beatty, New South Wales, Australia.

van Horne, B. 1983. Density as a misleading indicator of habitat quality. Journal of Wildlife Management 47:893901.

Whitaker, J. O., Jr. 1967. Habitat relationships of four species of mice in Vigo County, Indiana. Ecology 48:867-872.

White, G. C., D. R. Anderson, K. P. Burnham, and D. L. Otis. 1982. Capture-recapture and removal methods for sampling closed populations. Los Alamos National Laboratory, LA-8787-NERP, Los Alamos, New Mexico, USA.

Whitford, W. G., and Y. Steinberger. 1989. The long-term effects of habitat modification on a desert rodent community. Pages 33-44 in D. W. Morris, Z. Abramsky, B. J. Fox, and M. R. Willig, editors. Patterns in the structure of mammalian communities. Special Publication Number 28 of the Museum of Texas Tech University. Texas Tech University Press, Lubbock, Texas, USA.

Wiens, J. A. 1995. Landscape mosaics and ecological theory. Pages 1-26 in L. Hannson, L. Fahrig, and G. Merriam, editors. Mosaic landscapes and ecological processes. Chapman and Hall, London, UK.

Wiens, J. A., N. C. Stenseth, B. van Horne, and R. A. Ims. 1993. Ecological mechanisms and landscape ecology. Oikos 66:369-380.

Wiley, R. W. 1980. Neotoma floridana. Mammalian Species. Special Publication Number 139 of the American Society of Mammalogists. Shippensburg State College, Shippensburg, Pennsylvania, USA.

Wilson, C. P. 1998. Predator utilization of a fragmented habitat in Northeast Kansas. Thesis. University of Kansas, Lawrence, Kansas, USA.

Wolda, H. 1981. Similarity indices, sample size and diversity. Oecologia 50:296-302.

Wolff, J. O. 1995. On the limits of species-habitat association studies. Northwest Science 69:72-76.

Wolff, J. O., E. M. Schauber, and W. D. Edge. 1997. Effects of habitat fragmentation on the social dynamics of the graytailed vole. Conservation Biology 11:945-956.

Wootton, J. T. 1994. The nature and consequences of indirect effects in ecological communities. Annual Review of Ecology and Systematics 25:443-466.

Yao, J. R., D. Holt, P. M. Rich, and W. S. Marshall. 1999. Woody plant colonization in an experimentally fragmented landscape. Ecography 22(6):715-728.

Yarranton, G. A., and R. G. Morrison. 1974. Spatial dynamics of a primary succession. Nucleation. Journal of Ecology 68:780-790.

Zimmerman, D. L. 1993. A bivariate Cramer-von Mises type of test for spatial randomness. Applied Statistics 42:43-54. 